\title{
A TRANSEXUALIDADE E A TRADIÇÃO DO CANDOMBLÉ: GÊNERO E CULTURA EM DEBATE
}

\author{
TRANSSEXUALITY AND TRADITION OF CANDOMBLÉ: GENDER AND CULTURE IN DEBATE
}

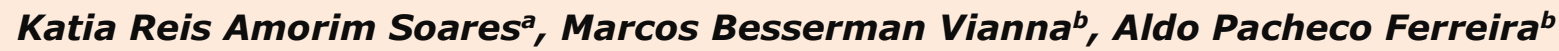 \\ Prefeitura Municipal de Duque de Caxias (PMDC) \\ Escola Nacional de Saúde Pública Sergio Arouca (ENSP/Fiocruz) ${ }^{b}$ \\ E-mail: aldopachecoferreira@gmail.com
}

\section{RESUMO}

O artigo explora o entrelaçamento do tradicional, do moderno e do pós-moderno na prática do Candomblé, discutindo a presença das pessoas transgêneras em seus cultos. Têm como hipótese a variedade de questões que impactam a tradição do Candomblé, como o corpo e as transformações corporais, a identidade, as indumentárias e a responsabilidade pela execução dos cargos. Trata-se de uma pesquisa exploratória, dedutiva e descritiva, onde além da revisão de literatura - bibliográfica e documental, foi realizada a observação participante. Os resultados mostram que por mais que se fale em avanços, as ações existentes são de sobremaneira muito incipientes e ainda carregadas de valores conservadores e preconceituosos. Cabe destacar a resistência das religiões tradicionais ancestrais dos cultos descendentes de matriz africana em receber no âmago de suas instituições religiosas, essa população transexual que tramita de forma mais ativa nos espaços sociais, culturais, políticos e religiosos, se ancora numa ancestralidade patriarcal, e nada mais é do que uma resistência a essa diversidade clara e viva que existe na sociedade brasileira; e assim, reproduz meios de aniquilação desses corpos não desejáveis nos espaços religiosos. Convém ressaltar que, apesar do grande esforço em esmiuçar as discussões acerca desta temática nas diversas instâncias das relações sociais, as suas possibilidades são inesgotáveis, o que evidencia a necessidade de se manter aberto o debate para novas contribuições, haja vista a complexidade do tema e a sua relação a tradições culturais do Candomblé.

Palavras-chave: Pessoas transgênero; Cultura; Identidade de Gênero; Tradição.

\section{ABSTRACT}

The article explores the intertwining of the traditional, the modern and the postmodern in the practice of Candomblé, discussing the presence of transgender people in their cults. Have as a hypothesis the variety of issues that impact the Candomblé tradition, such as the body and body changes, identity, clothing and responsibility for the execution of positions. It is an exploratory, deductive and descriptive research, where in addition to the literature review bibliographic and documentary, participant observation was carried out. The results show that no matter how much progress is said, the existing actions are extremely incipient and still loaded with conservative and prejudiced values. It is worth mentioning the resistance of traditional ancestral religions of African descent cults to receive at the heart of their religious institutions, this transsexual population that is more active in social, cultural, political and religious spaces, anchored in a patriarchal ancestry, and nothing it is more than a resistance to this clear and living diversity that exists in Brazilian society; and so, it reproduces means of annihilation of these undesirable bodies in religious spaces. It is worth mentioning that, despite the great effort to scrutinize the discussions about this theme in the various instances of social relations, its possibilities are inexhaustible, which highlights the need to keep the debate open for new contributions, given the complexity of the theme its relation to Candomblé cultural traditions.

Keyword: Transgender persons; Culture; Gender identity; Tradition. 


\section{INTRODUÇÃO}

O debate sobre sexualidade, identidade de gênero e orientação sexual está longe de ser harmônico. E, apesar dos avanços políticos, sociais e legais pode-se, ainda, afirmar que a população LGBT (lésbicas, gays, bissexuais, travestis, transexuais, transgêneros e intersexo) experimenta uma violência diária e cruel, sendo para uma sociedade cisheteronormativa, uma ameaça cultural, histórica, social e política, baseada no binarismo de gênero e no sexismo. Esses tipos de violências fazem do Brasil o país que mais mata LGBT, em especial, a população de transexuais e travestis no mundo (ARAGON, 2006; MENDES; SILVA, 2020).

A sigla LGBT pode ser usada para se referir a qualquer um que não é heterossexual ou não é cisgênero, ao invés de exclusivamente se referir as pessoas que são lésbicas, gays, bissexuais ou transgêneros (SHANKLE, 2006). Para reconhecer essa inclusão, uma variante popular, adiciona a letra $\mathrm{Q}$ para aqueles que se identificam como queer ou que questionam a sua identidade sexual; LGBTQ foi registrado em 1996 (THE SANTA CRUZ COUNTY IN-QUEERY, 1996). Porém a unificação da sigla tende a se identificar como LGBTQI+ (lésbicas, gays, bissexuais, transgêneros, transexuais, queer, questionadores, flexíveis, assexuais, poliamor, escravidão/disciplina, dominação/submissão e sadismo/masoquismo), englobando posições políticas regionais, ambiente discriminatório, bem como a situação dos direitos LGBT onde eles vivem (PILAึO; GOLDENBERG, 2012).

Conforme destaca Crescêncio et. al. (2017), no campo dos estudos conexos ao gênero humano, o cisgênero é a oposição do transgênero, uma vez que sua identidade de gênero está em consonância com o gênero que lhe foi atribuído ao nascer, ou seja, quando sua conduta psicossocial, expressa nos atos mais comuns do dia-a-dia, estando inteiramente de acordo com o que a sociedade espera de pessoas do seu sexo biológico. Butler (2003, p.101) aponta que "apesar da ausência do termo cisgênero em textos oficiais, é importante situar que o seu uso é empregado de maneira estratégica para enfatizar a perspectiva binarista vigente e, dessa forma: 1) expor que o gênero não é da ordem do natural; 2) que é um constructo a partir das convenções morais e sociais; e 3 ) que não está condicionado à existência de uma determinada genitália/órgãos reprodutivos, tal como discute".

Ann Oakley (1972) trouxe uma distinção no que se refere a sexo e gênero, uma vez que essas categorias eram percebidas como infinitamente conectadas. A autora conclui em Sex, Gender \& Society, que tais categorias são distintas, embora necessárias uma a outra, além de posicionar a categoria gênero no campo da cultura e da psicologia e alertar sobre o lugar da natureza destinado ao sexo. As contribuições da autora foram importantes, por apontar que a existência de corpos que não dialoga com o ideal de "normalidade", buscado pela sociedade existe e precisa ser vistos com cuidado e respeito. Essa contribuição é pertinente para os estudos de gênero e sexualidade também por seu caráter performativo, não estritamente na definição butleriana, mas no sentido de que o gestual e as genitálias não devem designar o sujeito per se (DIAS; ARAÚJO, 2017).

Stoller (1982) afirma que, o modelo hegemônico heterossexual reúne aspectos psicológicos, sociais, históricos associados à masculinidade, por um lado e à feminilidade, por outro. $\mathrm{O}$ forjamento desta noção decreta em definitivo que o sexo, no sentido anatômico, diferencia-se da identidade sexual e que tais elementos não são naturalmente correspondentes. Para o autor, a experiência transexual está diretamente ligada a um "distúrbio de identidade de gênero" e, portanto, essas pessoas são passíveis de cura. Estes corpos se constroem no decorrer de suas vivências e se fortalecem nelas. Portanto, subestimar as suas potencialidades é fadá-los a um não-lugar, à subalternização, ao esquecimento e, em última análise, à morte social e física dos sujeitos (OAKLEY, 1981).

O contexto que envolve o processo de negação dessa diversidade se esbarra em um sentimento coletivo muito mais profundo e doloroso que é a aniquilação desses corpos indesejáveis. Efetivamente, Malia (2019) traz em sua entrevista uma explicação muito contundente sobre a necessidade desse debate, de se fomentar a temática dentro dos terreiros de Candomblé: "Tratar desses temas nas comunidades-terreiro passa pelo modo como nós fomos socializados numa cultura binária na qual ou se é homem ou mulher". De fato, a construção binária da sociedade brasileira, carregada de tabus e mitos oriundos de uma cultura eurocêntrica, branca, patriarcal e cristã reforça a posição posta a esses corpos invisibilizados e mais, indesejáveis nos espaços sacrossantos.

Malia (2019) destaca, ainda, que sendo as comunidades/terreiros espaços onde circulam identidades de gênero e orientações sexuais diversas, bem como também existe "um contingente de pessoas de 
sexualidades dissidentes"; se faz importante ressaltar a necessidade do debate dentro desses espaços, uma vez que não se tratar apenas de um direito em "professar a fé" de cada indivíduo, o que é assegurado pela Declaração Universal dos Direitos Humanos (ONU, 1948) e pela Constituição (BRASIL, 1988). A partir destas questões, é exposta a tendência desse processo de negação sofrida pela população LGBT nos espaços religiosos do culto de Candomblé, a qual se encontra intrinsicamente relacionada a uma questão cultural e social binária, cisheteronormativa do que possivelmente com a questão da ancestralidade do culto.

Santos (2011) aponta que o Candomblé é, em sua composição, uma comunidade detentora de uma diversificada herança cultural, onde se mesclam elementos provenientes, sobretudo da África e no Brasil que abrigam minorias, e que buscam a aceitação e o acolhimento de uma pessoa tal como ela se apresenta socialmente, ou seja, tal qual a identidade de gênero que ela expõe, sem a necessidade de conversão a determinados juízos de valores ou ajustes sociais. É, também, uma religião com hierarquia, códigos e simbologias muito peculiares (BARBOSA JR., 2011). Silva (2019) sinaliza que "A comunidade ritualística (Égbé) do Candomblé tem para cada pessoa adepta, o seu lugar próprio e nenhuma pessoa fica aleatória dentro desse amálgama humano”.

Entretanto, as tarefas são atribuídas aos sujeitos com base em expectativas sobre as performances de gênero relacionadas à materialidade de seus corpos. Sendo assim, em muitos desses espaços, a pessoa trans não pode desempenhar funções díspares daquelas que não sejam reconhecidas em suas identidades de gênero. Essas interdições funcionam como se seus corpos, suas performances e suas identidades de gênero fossem descoladas uns dos outros e como se houvesse algo de prévio, de dado, de não produzido sobre eles (SANTOS; DALLAPICULA, 2020). Porquanto mulheres e homens, sejam cisgêneros ou transexuais, tem cargos e funções muito bem definidas, pontuadas, não sendo permitido que determinados postos estabelecidos para mulheres sejam exercidos por homens e/ou vice-versa; contudo, diante das discussões sobre as expressões sexuais e de gênero, como fica a pessoa trans iniciada nas casas de asé?

Este artigo se propõe a discutir a tradição dos terreiros de Candomblé em torno da presença da pessoa trans, buscando ressaltar os elementos internos da tradição, problematizando a ideia mesma de tradição, e alguns tópicos que são críticos no debate, como o corpo e as modificações corporais, a identidade, as vestimentas e a atribuição dos cargos.

\section{METODOLOGIA}

Trata-se de uma pesquisa exploratória, dedutiva e descritiva, onde além da revisão de literatura bibliográfica e documental, foi realizada a observação participante (BOURDIEU, 2005). O estudo realizado teve como orientação a seguinte pergunta: Como os Babalorixás e as Yalorixás estão percebendo a presença de pessoa trans nos cultos do Candomblé?

A observação participante é um processo de pesquisa científica no qual o pesquisador está presente na situação que se deseja compreender. Assim, ele mantém uma relação na qual colhe as informações ao mesmo tempo em que modifica e é modificado pela realidade que observa (SCHWARTZ; SCHWARTZ apud MINAYO, 1993). Como instrumento útil e privilegiado, a observação participante se constitui como estratégia profícua por possibilitar acesso mais próximo ao objeto estudado e por permitir maior riqueza da produção das informações da pesquisa (JACCOUD; MAYER, 2008). Nos diz Poupart: "Assim, misturar-se às atividades cotidianas dos atores, com ajuda da observação participante, constitui o melhor meio de perceber suas práticas e interações, como também de interrogá-los durante suas ações" (POUPART, 2008, pág. 217).

Para a etapa da observação participante, na qual estivemos dentro de um terreiro observando o cotidiano, entre 2018 e 2019, teve-se encontros semanais com três importantes mães de santo brasileiras, que praticavam/praticaram rituais de Candomblé na cidade de Duque de Caxias, Rio de Janeiro. Os encontros e conversas com as mães de santo e com outros interlocutores, ocorreram por um período de três meses, em cada novo encontro, que geralmente durava algumas horas, surgia uma nova informação, um novo conhecimento, aprofundando os resultados da pesquisa.

Para efeito do estudo com a revisão bibliográfica e documental, foi desenvolvida uma análise conceitual acerca das temáticas de gênero e religião, elaboradas em período aberto, sem delimitação temporal, observando a importância das informações que podem ser geradas a partir de uma visão crítica. Deste modo, o delineamento da pesquisa buscou identificar e compatibilizar produções afins, através da observação do objeto de investigação e a sinalização de diferentes perspectivas, favorecendo a identificação do estado da arte do tema de estudo (VOSGERAU; ROMANOWSKI, 2014).

Foi realizada busca eletrônica de artigos nas bases de dados da Biblioteca Virtual em Saúde (Medical Literature Analysis and Retrieval System Online (Medline), Literatura Latino-Americana e do Caribe em 
Ciências da Saúde (Lilacs)) e Scientific Eletronic Library Online (SciELO), com os descritores "pessoas transgênero" ("transgender persons"), "religião" ("religion"), "cultura" ("culture") e "identidade de gênero" ("gender identity"). No cruzamento das palavras foi adotada a expressão booleana: "AND" (inserção de duas ou mais palavras), escolhidos mediante consulta aos Descritores em Ciência da Saúde (DeCS) e Medical Subject Heading (MeSH). Os critérios de inclusão foram: artigos originais; disponibilizados online; nos idiomas português, inglês ou espanhol; com definição do método, cenário do estudo, população estudada, apresentação consistente dos resultados encontrados, com Brasil como país de assunto. Os critérios de exclusão foram: qualquer fator que não atendesse aos critérios de inclusão; estudos que apresentassem erros sistemáticos; estudos de revisão, relatos de caso ou comunicação; além de ambiguidade e apresentação insuficiente dos resultados.

Helder (2006) aponta que a pesquisa documental permite a investigação de determinada problemática não em sua interação imediata, mas de forma indireta, por meio do estudo dos documentos que são produzidos pelo homem e por isso revelam o seu modo de ser, viver e compreender um fato social.

Ao recolher documentos de forma criteriosa o pesquisador passa a gerenciar melhor o tempo e a relevância do material recolhido, o que para alguns autores constitui a pré-análise. Calado e Ferreira (2004), dizem que a atividade de coleta e pré-análise do documento, são duas tarefas que se completam e que se condicionam mutuamente. Deste modo, a tarefa de préanálise passa a orientar novas coletas de dados, considerando que o processo é realizado de forma mais prudente e cautelosa com a intenção de alcançar melhores resultados na análise crítica do material recolhido. Esta, por sua vez, tem como objetivo central averiguar a veracidade e credibilidade dos documentos adquiridos e a adequação destes às finalidades do projeto

Dessa forma, após o levantamento documental, o material foi estudado através da realização de fichamentos, que visam abranger todas as informações relevantes para o estudo, bem como sínteses de cada texto pesquisado. Lakatos e Marconi (2011) definem este tipo de fichamento como de "resumo ou de conteúdo", não possuindo julgamentos pessoais ou de valor. Paralelamente à realização dos fichamentos foi elaborado um fichário de sínteses pessoais constando reflexões e críticas à documentação. Esta etapa está associada ao que Cervo e Bervian (1975) denominam de "leitura informativa", a qual pode ser subdividida em quatro categorias de leitura relacionadas entre si: "leitura de reconhecimento", "leitura seletiva", "leitura crítica ou reflexiva" e "leitura interpretativa". O material fichado foi então organizado, o que nos permitiu cruzar os aportes dos diversos autores em relação ao tema de pesquisa.

Quanto aos aspectos éticos da pesquisa, foram observados os disciplinados pela Resolução 466/2012 do Conselho Nacional de Saúde Ministério da Saúde (BRASIL, 2012), Comitê de Ética da Escola Nacional de Saúde Pública Sergio Arouca/FIOCRUZ. Seguiu de modo criterioso e ético as necessidades específicas para a realização de uma pesquisa com seres humanos, sobretudo quanto a questões de voluntariedade e confidencialidade.

\section{O CANDOMBLÉ SOB O OLHAR DO BINARISMO}

O espaço do terreiro é de afirmação de uma religiosidade cada vez mais marginalizada por integrar diferentes comportamentos e expressões, inclusive de gêneros, e a crença coloca em evidência, como podemos desatrelar das pesquisas, identidades sexuais e de gênero que transitam entre o reconhecimento aos padrões normativos dominante e a sua transgressão (DIAS et. al., 2016; SANTOS; DALLAPICULA, 2020) compreendendo então, que apesar de todas as divergências e dificuldades, esses espaços são possíveis.

Não obstante, emerge um diálogo das casas de Candomblé quanto a questão do binarismo sob o olhar que descendem de uma cultura eurocêntrica, cristã, uma vez que códigos binários como bem-mal, certo-errado, céuinferno, masculino-feminino, não contemplam a pluralidade da pessoa humana para as tradições culturais de descendência africana, conforme citado por Santos (2008, p.151):

“A condição humana, por exemplo, não é expressa
pelo binário homem-mulher. No panteão do
candomblé existem orixás eminentemente femininos,
eminentemente masculinos, e orixás ambivalentes ou
andróginos, isto é, feminino e masculino ao mesmo
tempo. Essa trindade, esse terceiro, é a possibilidade
de várias expressões do humano sem reduzi-lo à
binaridade calcificante”.

É possível perceber que, apesar de compreender as divindades oriundas de terras africanas como elementos da natureza, energias do universo, muitos autores, pesquisadores e adeptos dos cultos de candomblé, buscam materializar estas energias ao longo da história a fim de compreender "o que são essas forças", "de onde vem", "como se materializam"? Com isso, surgiram ao longo da história de uma religião que chega a cerca de 10.000 (dez 
mil) anos de existência, uma tentativa de humanização das deidades africanas, a fim de melhor entendimento uma vez que se trata de uma tradição com base na oralidade. Essa humanização cria um vínculo ancestral dentro da cultura Nagô, em especial dos povos Yorubá com seus orixás através dos Itan conforme elucida Souza e Souza (2018, p.101):

"A palavra Itan é uma palavra de modo invariável mesmo quando for referida no plural. O Itan é o conjunto de mitos e lendas do panteão africano que narra as histórias envolvendo canções, danças, rituais e ensinamentos. Para os Yorubás é considerado como verdade absoluta sobre a criação do mundo, possuindo grande respeito por ter sido repassado oralmente como ensinamentos através dos mais velhos".

As religiões, em geral, têm negado às pessoas transexuais e travestis o direito de existir nas comunidades religiosas (SANTOS, 2008; SANTOS 2011). Os espaços religiosos, que deveriam acolher indistintamente as pessoas que os procuram para um bem-estar espiritual, têm afastado determinadas pessoas do convívio e da afetividade religiosa. E, um debate que muito contribui para esse entendimento, por vezes parece tão simples, mas extremamente complexo é a questão da vestimenta. O fato de uma pessoa transexual ser proibida de usar roupas que se identifiquem com o gênero que a mesma se reconhece, transcende a religiosidade e a forma hostil como muitas vezes isso é imposto, acaba por constituir uma relação abusiva de poder, onde homens e mulheres transexuais e travestis têm suas identidades de gênero negadas tal qual, outros espaços sociais e políticos. Essa postura, em geral, significa uma adesão às normas sociais de gênero e sexualidade impostas por uma sociedade evidentemente conservadora, cisheteronormativa excludente e perversa. $\mathrm{O}$ problema se agrava ainda mais em relação às identidades transexuais e travestis, em geral porque as suas próprias histórias, estigmatizadas socialmente, trazem o peso da existência de seus corpos indesejáveis e que já contestam e evidenciam pressupostos heteronormativos.

\section{O QUE DEFINE A ESSÊNCIA DO CANDOMBLÉ}

Para entender o Candomblé, é necessário vivenciar e, participar da vida religiosa do Egbé (comunidade). É em suas casas que se aprende a cultuar os diversos Orixás e todos os seus mistérios (SILVA, 2019). O aprendizado acontece pelos ensinamentos orais e pela repetição dos atos tradicionais de uma determinada Egbé e essa tradição é específica de cada nação e a raiz que identifica de onde este templo provém. Este, talvez, seja o principal elemento identificador de uma linhagem espiritual (BASSI, 2016). Acredita-se que, somente desta forma pode-se de antemão reconhecer a seriedade daquela casa, pois o Babalorixá ou a Yalorixá e seus iniciados, trazem a bagagem de conhecimento espiritual de sua casa matriz, ou seja, trazem o Asé, sua tradição, que perpetua desde a fundação daquele Asé (descendência) (PEREIRA; CHEVITARESE, 2019).

O Candomblé historicamente é uma religião familiar/tribal (CASTILLO; PARÉS, 2007). A perpetuação do Asé prescinde da iniciação de novos seguidores, no qual os pais iniciam seus filhos de acordo com o caminho apontado pelo Ori (cabeça espiritual, representação telúrica de Olorum) do futuro Yaó (iniciado) (JAGUN, 2019). Muitos desses iniciados são crianças ou adolescentes que assumem a religiosidade com suas obrigações e tabus, denominados de "quijila" (a maioria alimentar, como o exemplo dos iniciados em Oxalá que não devem comer nada que leve dendê), e outras que expõe mais o iniciado por exemplo, os fios de conta, as roupas brancas, kelê (gargantilha de iniciação feita de materiais diversos) (LIMA, 2003).

Cabe salientar que é nesta instância que aparecem os olhares de intolerância e atitudes de preconceito, isto em quaisquer esferas, algumas veladas, outras muito explícitas, conforme afirma Junsá (2014).

O culto aos Orisás é certamente um culto de mistérios, para o qual existe de fato, certa dificuldade em adquirir mais conhecimento sobre o mesmo, uma vez que seus ensinamentos acontecem através de uma linguagem oral e escrita próprias que sofrem interferências por diversas questões como: a própria oralidade ou pelos diversos dialetos, em especial, os utilizados pelo povo bantu da nação Angola/Congo, como kimbundo, kinkongo, tchokwe, dentre outros (JAGUN, 2019), ou ainda pela influência de outras nações, tribos quando chegaram posteriormente ao Brasil (BASSI, 2012). Mistérios estes, naturais da cultura negra massacrada pela escravidão, pela necessidade de praticá-lo no obscurantismo das senzalas e que contribuiu para a disseminação de irrealidades que geram cada vez mais preconceito, principalmente, vindo dos membros de outras práticas religiosas que acreditam na superioridade de suas crenças (SANTOS; DALLAPICULA, 2020). Conforme afirma Braga (1995, p.23):

"A quantidade e variedade de diversos povos africanos (iorubas, congos, angolanos) que chegaram ao Brasil, junto ao povo europeu e nativos indígenas deram origem a uma cultura híbrida, um povo ladino e crioulo, mestiços na cor, na cultura, nos hábitos, crenças e valores". 
A colonização portuguesa trouxe para as terras brasileiras seus hábitos, valores e costumes moldados pela Igreja Católica Apostólica Romana e estes, eram constantemente desafiados por esta pluralidade de raças, culturas e crenças, o que torna o Brasil, cenário de muitas perseguições em nome da hegemonia da Igreja Católica (PRANDI, 2004). E, os resíduos desta história foram trazidos para os dias atuais, com uma nova roupagem de "tolerância" em conformidade com as legislações instituídas durante a história para combater práticas como preconceito, discriminação, racismo, segregação, xenofobia, intolerância e perseguição religiosa (OXAGIYAN, 2002).

De acordo com Miranda et. al. (2012), depois de longo período de miscigenação da etnia brasileira, a sociedade passou por uma tentativa de branqueamento promovido por uma elite dominante, latifundiária e escravagista com o interesse de estabelecer um padrão de civilização inspirada num modelo europeu, visto com supremacia, uma vez que a "mistura" é fonte de decadência para a raça superior.

Somado a esta miscigenação dos povos no desenvolvimento de novas crenças, destaca-se o misticismo das práticas religiosas dos negros que contribuíram para disseminar o medo e a ideia de que o negro não tinha alma (LODY; SILVA, 2002). Tal misticismo forjou a uma imagem de práticas do "mal", de um culto desenvolvido através de manifestações de magia negra, proporcionando forte tendência de se relacionar tudo que é ruim, do mal, desconhecido a algo 'negro', o que se tornou um costume linguístico que persiste até os dias de hoje (BASSI, 2012).

Destarte, ao fazer uma reflexão quanto aos reais motivos dos indivíduos recorrerem a sua devoção espiritual, seja ela qual for, deixa claro que nenhuma prática religiosa se limita em si mesmo, na busca de religiosidade puramente dita, ou seja, ela contém todo um emaranhado de valores culturais, políticos e sociais que se pretende impor a um povo, na maioria das vezes em benefício próprio ou de um grupo. A questão não se limita na busca de um espaço para praticar a fé, o que alguns grupos religiosos almejam, na verdade, é a construção de uma sociedade com base nos valores idealizados que pretendem alcançar, subjugando todo e qualquer ideal que difere de suas referências (TERRIN, 1998).

Pereira e Chevitarese (2019) apontam que devido à forte tendência do pensamento cultural monoteísta, é comum verificar que as práticas religiosas divergentes são encaradas com base em termos de "satanismo", como "eixo do mal", "expressões maléficas", "adorações diabólicas" para combater práticas religiosas que divergem do ideário desejado, proporcionando certa animosidade no que tange as relações com o 'outro'.

Durante muitos séculos, guerras são travadas em todo o mundo na busca da imposição de uma verdade que se define como o caminho correto (HOBSBAWM, 2014). Caminho esse, potencialmente responsável por promover espaços de subalternidade e invisibilidade para corpos não-desejáveis, que ferem a hegemonia da cisheteronormatividade: a verdade absoluta (SEPULVEDA; SEPULVEDA, 2017). Esta não é uma prática exclusiva de um único segmento religioso, muito pelo contrário, a Igreja católica teve sua participação muito avivada em longo período da história. Contudo, em um período temporal mais recente, entre as décadas de 1970 e 1980, com o surgimento das seitas neopentecostais em território nacional, iniciou-se um processo de desqualificação de quaisquer outras vertentes religiosas, que não corroborassem com a visão bíblica da verdade do deus UNO, já mencionado. Diante a essa realidade observada, foi configurado no inconsciente coletivo das igrejas neopentecostais, que de todos os segmentos divergentes, as religiões de matrizes africanas, apresentavam a totalidade de seus males (TEIXEIRA, 1987).

Diante dessa perseguição promovida ao longo da história contra o negro escravizado, sua cultura, seus cultos, não obstante, acabou provocando essa aproximação dos cultos de Candomblé com os movimentos sociais dos excluídos socialmente promovendo essa aproximação entre os movimentos e a religião. Bezerra (2019) ressalta que, o período entre o final da décadas de 1960 e 1970 foi marcado pelo despertar de diversos movimentos sociais, com destaque para os movimentos estudantis, os movimentos feminista e homossexual (mais tarde identificado como Movimento LGBT) e o fortalecimento do movimento negro que utilizou recursos como a música, através de ritmos como Soul Music e da moda como o estilo Black Power e mais tarde, já na década de 1980 o Hip Hop, promoveram um trabalho de conscientização da importância na luta da população negra no combate ao preconceito, na eliminação de todas as formas de discriminação e na garantia da inserção da cultura africana e afro-brasileira nos espaços sociais e políticos do país.

Estas manifestações insurgentes tinham como objetivo combater a proliferação social, política e cultural de ideologias que enalteciam a primazia de valores morais, religiosos, tabus, regras e padrões socialmente construídos à luz de um modelo europeu (branco), cisheteronormativo, conservador, que repelia toda a história, a cultura, as crenças, a música, descendentes de 
uma raça negra e tida como inferior.

É importante destacar que as conquistas desses movimentos ao longo de toda história são relevantes, porém não conseguiram conter a astúcia das diversas formas de dominação burguesa no Brasil e no mundo que segue promovendo um vasto caminho de preconceito, intolerância e violência sobre todos os coletivos que não se enquadram no padrão de normatividade imposto de forma vertical por essa autocracia burguesa.

$\mathrm{Na}$ busca por uma compreensão melhor acerca desta temática, é importante ressaltar que, toda e qualquer ação praticada contra um cidadão no exercício dos seus direitos instituídos é crime (seria isso?). Porém, mais que isso, é necessário refletir quanto a esta prática preconceituosa e excludente que promove prejuízo à Dignidade Humana. Como evidencia a definição de violência da autora Chauí (2015, p.308):

"Fundamentalmente, a violência é percebida como uso da força física e do constrangimento psíquico para obrigar alguém a agir de modo contrário à sua natureza e ao seu ser ou contra sua própria vontade. Por meio da força ou da coação psíquica, obriga-se alguém a fazer algo contrário a si, aos seus interesses e desejos, ao seu corpo e a sua consciência, causando-lhe danos profundos $e$ irreparáveis $\{\ldots\}$...'

O crescimento do uso da violência nas relações sociais e interpessoais provocou ao longo da história a necessidade de se criar estratégias de combate e controle bem como, um aparato legal que promova a segurança e o acesso aos direitos dos indivíduos em toda sua diversidade.

\section{A TRADIÇÃO RELIGIOSA DO CANDOMBLÉ}

Birman (2005) aponta que, um dos temas mais polêmicos na atualidade dos terreiros de candomblé é a experiência da transgeneridade: o fato de que pessoas que nasceram com uma genitália relacionada socialmente a um determinado sexo se identificarem existencialmente com o outro sexo ou, de outras formas, recusarem essa designação social do gênero ocorrida em seu nascimento.

Esse fenômeno está ligado com o que os estudos sobre subjetividade chamam de identidade de gênero (BUTLER, 2003), ou seja, como as pessoas experimentam sua presença no mundo através de relações de identificação (ou não identificações) com imagens culturalmente construídas do masculino e feminino em relação aos corpos das pessoas, tencionando ideias naturalizadas do que significa ser homem e mulher e que ligação teriam essas ideias com os corpos em suas múltiplas experiências.

Tal questão, até pouco tempo silenciada nos terreiros de Candomblé, vem sistematicamente aparecendo, de maneira que já não se pode mais se furtar às questões que ela traz para $o$ interior dessas comunidades (LEMOS, 2019). De tal forma, surge a discussão que possa oferecer alguns elementos que subsidiem o debate, que se faz necessário e que se situa polemicamente nos terreiros. Apesar de ainda existirem poucas produções sobre este assunto, é possível perceber o crescimento do debate não só entre seus pares (homens e mulheres trans e travestis) como também entre os adeptos aos cultos de matriz africana.

Dentre as entrevistas que se têm acesso em seu livro, é importante destacar para esse contexto a fala muito apropriada de um membro de terreiro que o autor chama de Airá, preservando sua identidade, Lemos (2019, p. 64) afirma que:

\begin{abstract}
"Dentro das casas de Candomblé até hoje só sabiam da existência dos homossexuais, do gay e da lésbica. Antes de ter essa sigla LGBT era homossexual masculino e homossexual feminino \{...\} as casas de candomblé ainda não estão envolvidas nesses assuntos \{...\} sei que o orixá aceita todos, suas lutas, suas convenções e sua fé, pode ser rico, pobre, branco, preto, a casa de candomblé ela aceita. \{...\} sendo que esse assunto ainda não chegou nas nossas casas".
\end{abstract}

Os terreiros de Candomblé são parte do processo histórico de formação do espaço geográfico brasileiro e, parte deles, têm organicidade própria. Isso quer dizer que nossas práticas e olhares do mundo são orientados pelo viés da tradição. Mas o que seria a tradição? Muitas vezes somos tentados a pensar em tradição como sendo aquilo que não muda, que permanece o mesmo de geração em geração, sendo, portanto, estática (SEPULVEDA; SEPULVEDA, 2017). Entretanto, as noções africanas de tradição têm muito mais a ver com a dinâmica da transmissão do que com a estática de uma experiência conservada (AGUESSY, 1980).

A palavra tradição, tal como a utilizamos, é advinda do latim tradere que significa transmitir; desse modo, tradição seria um sinônimo de transmissão. Tradição significa que ensinamos e aprendemos o conhecimento e práticas fundamentais e básicos para a compreensão de nossa existência e para os parâmetros de avaliação de nossas ações (BASSI, 2012). Até aqui, parece que a definição é pacífica; entretanto, o problema se coloca quando precisamos saber o que é fundamental ou basilar 
para compreender nossa existência e o que necessitamos para orientar nossas ações. Conforme argumenta Iniesta (2010), transmissão do quê? Do que é realmente importante.

Se o corpo é templo do orixá, isso significa que o templo deve permanecer sempre do mesmo modo? Quais os limites para o que pode ser modificado em um corpo para que ele siga permanecendo templo das divindades? As vestimentas utilizadas permaneceram as mesmas do decorrer dos tempos? O que nelas se modifica e qual o sentido dessas modificações? As divisões das tarefas do terreiro, em função do tipo de corpo, são universais? Permanecem invariavelmente a todo o tempo? Todas essas questões podem ser colocadas para relacionar o que entendemos como tradição e o que esse entendimento impacta do cotidiano dos terreiros em relação com o que se pensa sobre o que permanece no tradicional (NASCIMENTO, 2019).

\section{A INSERÇÃO DA POPULAÇÃO TRANS NAS CASAS DE CANDOMBLÉ}

Todos os movimentos coletivos acabaram aproximando as massas e, com isso, o aumento de pessoas do movimento LGBT adeptos dos cultos afro-brasileiros cresceu por todo país (NASCIMENTO, 2019), uma vez que em meio as violências vivenciadas emergem a necessidade de amparo psicossocial que de alguma forma caminha junto com a necessidade de fortalecimento espiritual e o exercício da fé (GUIMARÃES, 2003), o que é algo inerente do ser humano ao longo de toda história, bem como assegurado em Carta Magna no Brasil (BRASIL, 1988).

Devido a esta associação do culto de Candomblé ao negro, oriundo de um período escravocrata, esta religião era vista como inferior, subalterna às demais, conforme explicitado em capítulo anterior e com isso, também sempre fora reconhecida como uma religião acolhedora dos indivíduos excluídos por uma sociedade branca dominante, onde os indivíduos não poderiam ser o que eles são naturalmente. Sendo assim, eram os templos, as casas de Candomblé que iriam acolher o gay, a prostituta, o pagão. Não obstante afirma Birman (1991, p.38):

"Lugar de bichas, tem-se como certo. Suspeitas sobre a masculinidade de seus pais-de-santo são esperadas. Esta marca (por vezes) infeliz faz parte da imagem dos homens que se vinculam aos terreiros. Alguns se antecipam. Afirmam de maneiras variadas a condição de membros efetivos desse peculiar contingente; são pais e filhos-de- santo bichas, personagens que habitam o universo urbano nos seus espaços mais decididamente públicos, seus meios de comunicação - apresentamse em jornais, revistas e programas de televisão e fazem parte do reservatório de tipos sempre explorados nos programas de humor. A associação entre campo religioso afro e sexualidade constitui, pois, referência de uso corrente e objeto permanente de discussões nas conversas sobre as casas de santo. Nestas conversas busca-se formular uma resposta satisfatória para esse fenômeno: "por que tem tanta bicha nas casas de Candomblé”.

Como entender esta relação de paterno/materno dessas comunidades religiosas para com essa população gay, perseguida e excluída por uma sociedade seletista e excludente amparada numa ideologia cristã que irá demonizar os indivíduos com base em valores morais, religiosos, sociais e culturais de uma sociedade hegemônica europeia?

É possível reconhecer que não são as religiões que dão origem ao preconceito, pois todas têm um núcleo humanizador ou deveriam ter. A origem do preconceito está dentro da condição humana. As religiões na verdade, aspiram o aperfeiçoamento do ser humano e todas elas são fruto de um preenchimento cultural do processo de construção simbólica de uma identidade também cultural. E, são estes mesmos dados culturais que vão determinar outros valores sociais como o machismo, o preconceito e qualquer outro padrão de relacionamento humano. O que torna possível perceber que apesar das religiões descendentes de matriz africana ainda serem as religiões que mais acolhem a população LGBT, este ainda é um espaço de opressão e discriminação que fere a identidade principalmente da população $\mathrm{T}$ (Trans e Travestis). Uma vez que, lhe é negado o pleno exercício de sua identidade de gênero e sua religiosidade assegurada hoje pela Carta Magna no Brasil (BRASIL, 1988) e demais legislações, Declarações, Resoluções, de forma que essas identidades também são excluídas e negadas dentro dos terreiros de Candomblé.

Devido à associação histórica do culto de Candomblé ao negro escravizado, esta religião que sempre fora reconhecida como uma religião sem regras, associada a promiscuidade, festas, músicas; onde os indivíduos poderiam ser o que eles são naturalmente, onde seus adeptos foram os primeiros a ousar brincar com os gêneros em suas vestimentas, com isso, eram as casas de Candomblé que iriam acolher o gay, a prostituta, o pagão, enfim, toda população que por qualquer motivo vivia à margem da sociedade dominante ao longo da história (BASSI, 2016). Mas, segundo Lemos (2019), percebe-se 
mudanças significativas dentro destas comunidades religiosas, uma vez que apesar das religiões descendentes de matriz africana ainda serem as religiões que mais acolhem a população LGBT nos dias de hoje, este também vem se tornando um espaço de opressão e discriminação, que segrega e fere a identidade principalmente da população trans. Ressalta Nascimento (2019, p. 128):

"Olha, infelizmente não dá, porque você tem que usar saia, é uma regra do Candomblé e não podemos ser flexíveis com você e desde então três meses não vou mais lá".

É importante analisar o quanto é perturbador para quem recebe essa exigência incisiva, uma vez que é possível perceber que o contexto transcende a "saia", o "camusu", a "bata", o "pano da costa". Conforme salienta Lemos (2019), muitas pessoas trans, adeptas do culto alegam inclusive não ter problema em "vestir a saia", contudo se faz necessário compreender o que está para além disso. É reconhecer um processo de negação que existe ali naquele espaço. "Aqui" você não pode ser quem você "diz que é". Toda luta, resistência, dores vivenciadas até o momento caem por terra e o que prevalece é o sexo biológico do seu nascimento, conforme ratificam Santos e Dallapicula (2020, p. 166), em um debate sobre transmasculinidades, onde pontuou sobre a questão do uso de vestimentas femininas dentro das casas de candomblé e afirmou que durante sua pesquisa entrevistou 52 (cinquenta e dois) homens Trans e transmasculinos em todo Brasil, dos quais apenas 2 (dois) são respeitados e acolhidos conforme sua identidade de gênero Trans.

Lemos (2019, p.84), menciona em sua pesquisa sobre o lugar de pertencimento e não-pertencimento dos corpos trans dentro dos rituais do Candomblé, identificando que, geralmente, mesmo nesse território repleto de expressões e símbolos de gênero, é possível identificar um lugar "marginal" para essas identidades tidas como "anormais", "fora do contexto". O autor indaga ainda que "Mesmo o Candomblé tendo ganhado fama de religião inclusiva, nos resta perguntar a quem o Candomblé está incluindo?’.

É notória a demarcação cruel de território. "Este lugar não é para você" endossando um espaço de preconceito, de segregação que põe por terra todo um trabalho de luta, de resistência, de ocupação de espaço, conquistado por essa população massacrada, estereotipada, conforme afirma Giulianna Nonato, travesti iniciada no Candomblé: "Não vou dizer que foi fácil. Eu sou travesti; portanto, não há espaço nesse mundo que eu possa habitar sem causar desconforto e estranhamento - a não ser a esquina" (NONATO, 2020).
Fica claro que esse processo de "Ligação" ou "Religação" vai para além do exercício da fé, para além da devoção religiosa, esse processo abarca outras questões importantíssimas para o desenvolvimento da pessoa humana como a convivência, a autoestima, empoderamento social, e mais que isso, o processo de negação desses corpos trans na sua essência social reforça o estigma de que essa população não é benvinda, ela é tolerada nos espaços previamente demarcados por uma sociedade hegemônica, cristã, cisheteronormativa que irá determinar "onde pode", "como pode", "de que forma pode".

Lemos (2019, p. 81/82) em meio a sua pesquisa, faz uma análise do quão nocivo pode ser essa inserção da população Trans no Candomblé ao contrário do que se esperava desse encontro sacrossanto:

\begin{abstract}
"Percebi que a religiosidade e a espiritualidade poderiam ser como uma alavanca em combate a uma das vulnerabilidades mais perversas que nós pessoas trans enfrentamos que é a solidão nesses trânsitos e nessas trajetórias vividas por nós. Não ter acesso a uma série de coisas como saúde, educação, família, segurança pública, emprego, moradia e somando a solidão tudo isso é doloroso e desesperador. Quando se vivencia todas essas vulnerabilidades, encontrar um amparo é fundamental. As religiões de matrizes africanas são conhecidas pelo processo de inclusão social em relação às demais religiões \{...\}.
\end{abstract}

É possível entender através da reflexão acima, como seria importante para as pessoas que buscam esse amparo religioso, inerente do ser humano, encontrar nesses espaços o conforto espiritual e humanizador do qual se espera. Por tratar-se de uma necessidade humana, é possível perceber que existe aí uma linha tênue entre o existir, o pertencimento e o desistir, o invisível. Quantas mortes ainda serão necessárias para que a sociedade de forma geral reconheça a existência dessa diversidade humana e entenda que o universo é capaz de acolher a todos numa convivência pacífica. Não existe raça superior, religiões superiores, gênero capaz de se sobrepor a outros. A religião tem um grande papel nesse contexto social que é de fato a "Re Ligação" com a espiritualidade e o compromisso social com o próximo.

Pensar na população de travestis e transexuais dentro das casas de Candomblé hoje é propor uma análise de como essas identidades perpassam pelos espaços privados, sociais e políticos dentro de uma sociedade patriarcal com severo recorte conservador e sexista. As identidades e os papéis sexuais estão, portanto, inscritos no domínio do social e do cultural. Santos (2008, p. 149) 
sinaliza:

\begin{abstract}
"No que concerne aos Terreiros de Candomblé, é necessário admitir que os valores específicos do povo de santo somam-se ou fundem-se às ideias dominantes na sociedade mais ampla. Não se pode falar de um sistema simbólico independente, mas sim da reprodução ou reinterpretação, parcial ou integral, do discurso hegemônico sobre a questão da sexualidade e de seu exercício, presente na sociedade brasileira abrangente".
\end{abstract}

Sendo assim, é possível ver nos dias de hoje, que estes espaços que já foram tidos como os mais acolhedores para essa população perseguida e marginalizada, transformaram-se em um espaço que segrega, excluí e nega as identidades de gênero em sua diversidade (conquista histórica, resultante de muita luta e resistência). É importante que se fale sobre essa solidão vivenciada principalmente por uma população trans que transita em meio a uma população conservadora, preconceituosa e excludente e mais, é necessário que se tome consciência que essa solidão, o esvaziamento do ser, adoece e mata as pessoas. Quando um espaço que deveria acolher e fortalecer os indivíduos, na verdade está desagregando e ceifando vidas.

É importante pensar em como estão sendo produzidas regras? Até onde vai o Divino e o Ser Humano? Quem discrimina, segrega? (JAGUN, 2019). Segue o autor, Jagun (2019, p.88):

"A gestão dos terreiros é feita diretamente pelo(a) líder religioso(a): Bàbálórìsà (Pai de Santo), ou pela İyálórìsà (Mãe de Santo), ou ainda por pessoa(s) designada(s) por estes. Mas, as regras são estabelecidas em um sistema teocrático. Ou seja, as leis divinas são as leis dos homens".

Pensar os cultos das deidades ancestrais do Candomblé no Brasil como mecanismos de segregação provoca uma inquietação tendo em vista a construção acerca das casas acolhedoras que sempre receberam e continuam acolhendo uma população excluída de seus lares bem como de toda sociedade, conforme salientam Oliveira; Souza; Paula (2020):

\footnotetext{
"O sistema mítico do candomblé não é fragmentário nem excludente; é totalitário - no sentido de abranger o ser humano como um todo -, e integrativo. Os mitos, os processos de iniciação, os rituais, enfim, toda a estrutura mítica do candomblé obedece a uma lógica própria, lógica essa que concebe o tempo e o espaço diferentemente de como
}

os concebe o mundo racional, baseado em axiomas científicos, do ocidente. Enquanto o que regula a sociedade capitalista ocidental é o tempo cronológico, tempo medido sempre pela produção do capital, tempo, enfim, sempre capitalizado, no candomblé prevalece o tempo mítico. Enquanto o primeiro é fragmentado e linear o segundo se realiza plenamente dentro de um ciclo que abarca a totalidade do ser humano".

Outrossim, o Candomblé, baseado na crença na ancestralidade africana, diviniza forças da natureza e busca reconectar os seus adeptos às suas origens ancestrais. Trazido ao Brasil pelas pessoas negras escravizadas, se expandiu em parte do território brasileiro, se reconfigurou, e é constituído por uma diversidade de cultos, assim como ocorre no continente africano, onde é realizado em regiões específicas, em geral, a partir de clãs (OXALÁ, 2005). E, sendo uma das religiões de matriz africana, tem uma organização social e política própria, um contexto específico e, como não poderia ser diferente, também sofre os impactos das normatividades de gênero e sexualidade que vigoram na sociedade.

O comparecimento de pessoas transgêneras no Candomblé não é nenhuma novidade (SANTOS, 2008). O que parece "novo" é o debate sobre quais lugares as pessoas transgêneras podem ocupar dentro dos terreiros e sobre as consequências das eventuais transformações corporais (ex.: silicone, cirurgias de redesignação sexual) para a presença das pessoas Trans nas rotinas de um terreiro de Candomblé. O debate está organizado, normalmente, em torno de quatro dimensões: o lugar do corpo no terreiro e em suas dinâmicas ritualíticas; o "direito" à modificação corporal e seus impactos na rotina da pessoa que fez esta modificação, durante sua presença no terreiro; a questão das vestimentas no cotidiano do terreiro; e, por fim, quem pode ocupar determinados cargos ou funções dentro do terreiro (OLIVEIRA et. al., 2020). Cada uma dessas dimensões está vinculada com pressuposições, nem sempre debatidas o suficiente, sobre os modos como as tradições africanas instaladas no terreiro pensam os fenômenos relativos a cada uma dessas dimensões.

\section{CONSIDERAÇÕES FINAIS}

Os estudos que analisaram a transexualidade e a tradição nos terreiros de Candomblé indicaram que, muito embora as suas portas estejam sempre abertas para todas as pessoas, algumas restrições são mantidas em favor da manutenção da tradição religiosa. As pessoas que dirigem as casas de Candomblé, em geral, conduzem seus terreiros 
à luz dos ensinamentos das pessoas mais velhas e, por isso, temas como a transexualidade ainda não se tornaram caros para essas comunidades. O que há, nos parece, são acordos de aceitação nos moldes de outras expressões religiosas: aceitar desde que as pessoas se adequem às normas de gênero e sexualidade vigentes nas comunidades-terreiro, que são aquelas pautadas pela perspectiva heteronormativa e cisgênera.

Apesar de considerar as vivências das sexualidades não cisgêneras e das transexualidades e das travestilidades como um tabu a ser quebrado, movimentos contra hegemônicos a esta visão estão surgindo em diversas casas de asé pelo Brasil afora. Ainda que existam algumas figuras do clero candomblecista pensado sobre a moral sexual dentro do culto afro-brasileiro e a necessidade de repensar seus conceitos, o laico vem ganhando protagonismo nessas questões.

Entretanto, fica evidente ao longo desta pesquisa que por mais que se fale em avanços, as ações existentes são de sobremaneira muito incipientes e ainda carregadas de valores conservadores e preconceituosos. Convém ressaltar que, apesar do grande esforço em esmiuçar as discussões acerca desta temática nas diversas instâncias das relações sociais, as suas possibilidades são inesgotáveis, o que evidencia a necessidade de se manter aberto o debate para novas contribuições, haja vista a complexidade do tema e a sua relação às tradições culturais milenares.

\section{Agradecimentos}

A Nzambi, pelo dom da vida. A Njila, por mostrar o caminho. A Superintendência de Políticas LGBT, da Subsecretaria de Estado de Promoção, Defesa e Garantia de Direitos Humanos/Secretaria de Estado de Desenvolvimento Social e Direitos Humanos do Rio de Janeiro. Ao Centro de Cidadania LGBT da Capital/RJ.

\section{REFERENCES}

AGUESSY, Honorat. Visões e percepções tradicionais. In: SOW, A.I. et. al. Introdução à Cultura Africana. Lisboa: Edições 70, 1980 .

ARAGON, Angela Pattatucci. Challenging Lesbian Norms: Intersex, Transgender, Intersectional, and Queer Perspectives. Haworth Press, 2006.

BARBOSA JR., Ademir. O essencial do Candomblé. São Paulo: Universo dos livros, 2011.

BASSI, Francesca. Revisitando os tabus: as cautelas rituais do povo de santo. Religião e Sociedade, vol. 32, n. 2, p. 170 193, 2012.

BASSI, Francesca. Os rituais: eventos, agências e eficácias no Candomblé. Religião e Sociedade, v. 36, n. 2, p. 244-265, 2016.

BEZERRA, Juliana. Movimento negro. Disponível em https://www.todamateria.com.br/movimento-negro/

BIRMAN, Patrícia. Relações de Gênero, Possessão e Sexualidade. PHYSIS - Revista de Saúde Coletiva, vol. 1, n. 2, p. 37-56, 1991.

BIRMAN, Patrícia. Transas e Transes: Sexo e gênero nos cultos afro-brasileiros, um sobrevoo. Estudos Feministas, vol. 13, n. 2, p. 403-414, 2005. https://doi.org/10.1590/S0104026X2005000200014.
BOURDIEU, Pierre. Esboço de autoanálise. São Paulo: Companhia das Letras, 2005.

BRAGA, Julio Santana. Na gamela do feitiço: repressão e resistência nos Candomblés da Bahia. Salvador: Edufba, 1995.

BRASIL. Constituição da República Federativa do Brasil. Dispõe sobre a Constituição da República Federativa do Brasil. Supremo Tribunal Federal. 1988.

BRASIL. Ministério da Saúde. Conselho Nacional de Saúde. Resolução No 466, de 12 de dezembro de 2012. Disponível em: https://www.iesb.br/Cms_Data/Contents/Portal/Media/arquivo s/466.pdf

BUTLER, Judith. Problemas de Gênero: feminismo e subversão da identidade. Rio de Janeiro: Civilização Brasileira, 2003.

CALADO, Cristina; FERREIRA, Cristina. Análise de documentos: método de recolha e análise de dados. Disponível em: http://www.educ.fc.ul.pt/docentes/ichagas/mi1/analisedocume ntos.pdf

CASTILLO, Lisa Earl; PARÉS, Luis Nicolau. Marcelina da Silva e seu mundo: Novos dados para uma historiografia do Candomblé Ketu. Afro-Ásia, vol. 36, p. 111-151, 2007. 
CERVO, Amado Luiz; BERVIAN, Pedro Alcino. Metodologia científica. São Paulo: McGraw-Hill do Brasil, 1975.

CHAUÍ, Marilena. Convite a Filosofia. $13^{\circ}$ Edição. São Paulo: Ática, 2015.

CRESCÊNCIO, Cintia Lima; SILVA, Janine Gomes; BRISTOT, Lidia Schneider. Histórias de gênero. São Paulo: Verona, 2017.

DIAS, Claudenilson; ARAÚJO, Rosangela. Aproximações e disjunções: a transexualidade e algumas perspectivas feministas. Seminário Internacional Fazendo Gênero 11 \& 13th Women's Worlds Congress (Anais Eletrônicos). Florianópolis, 2017.

DIAS, Karollyne Magalhães; MELO, Miguel Ângelo Silva de; QUEIROZ, Zuleide Fernandes. Práticas pretagógicas excludentes da cosmovisão africana em torno da homossexualidade. Revista Interfaces - Saúde, Humanas e Tecnologia, vol. 3, n. 11, 2016, p. 43-47.

GUIMARÃES, Marco Antonio Chagas. Tradição religiosa afro-brasileira como espaço de equilíbrio. In: SILVA, J.M. (org.). Religiões Afro-Brasileiras e Saúde. São Luís: AtóIre/Centro de Cultura Negra do Maranhão, p. 41-51, 2003.

HOBSBAWM, Eric. Introdução: A invenção das tradições. In: HOBSBAWM, Eric; RANGER, Terence. (orgs.). 9a ed. A invenção das Tradições. São Paulo: Paz e Terra, 2014.

INIESTA, Ferran. El pensamiento tradicional africano: Retorno al planeta negro. Madrid: Casa África, 2010.

JACCOUD, Mylène, MAYER Robert. A observação direta e a pesquisa qualitativa. In: A Pesquisa qualitativa: enfoques epistemológicos e metodológicos. Petrópolis, RJ: Vozes, 2008.

JAGUN, Márcio. Ewé: a chave do portal. Rio de Janeiro: Litteris, 2019.

JUNSÁ, Inzo Lemba Bojinã. Culto aos Jinkisi na Inzo Lemba Bojiña Junsá. Templo Religioso Angola Congo. 22/03/2014. Disponível em: https://sitebarra.com.br/v7/documentarioregistra-a-trajetoria-e-os-saberes-tradicionais-do-ponto-dememoria-capixaba.html

LAKATOS, Eva Maria; MARCONI, Marina de Andrade. Metodologia científica. 6. ed. São Paulo: Atlas, 2011.

LEMOS, Kaio. No Candomblé, quem é homem e quem não é? Rio de Janeiro: Metanóia, 2019.

LIMA, Vivaldo da Costa. A Família de Santo nos Candomblés Jêjes-Nagôs da Bahia. Salvador: Corrupio, 2003.
LODY, Raul; SILVA, Vagner Gonçalves. Joãozinho da Goméia: o lúdico e o sagrado na exaltação ao Candomblé. In: SILVA, Vagner Gonçalves. (Org.). Caminhos da alma: memória afro-brasileira. São Paulo: Selo Negro, 2002.

MALIA, Ashley. Por que Claudenilson está discutindo identidades trans dentro do Candomblé? Correio Nagô. 2019. Disponível em: https://correionago.com.br/portal/porque-claudenilson-esta-discutindo-identidades-trans-dentro-docandomble/

MENDES, Wallace Goes; SILVA, Cosme Marcelo Furtado Passos da. Homicídios da População de Lésbicas, Gays, Bissexuais, Travestis, Transexuais ou Transgêneros (LGBT) no Brasil: uma Análise Espacial. Ciência \& Saúde Coletiva, vol. 25, n. 5, p. 1709-1722, 2020. https://doi.org/10.1590/141381232020255.33672019

MINAYO, Maria Cecília de Souza. Desafio do conhecimento: pesquisa qualitativa em saúde. São Paulo - Rio de Janeiro, Hucitec - ABRASCO, 2 edição, 1993.

MIRANDA, Claudia; LINS, Mônica Regina Ferreira; COSTA, Ricardo Cesar Rocha da. Relações Étnico-Raciais na Escola: desafios teóricos e práticas pedagógicas após a Lei no 10.639. Rio de Janeiro: Quartet, 2012.

NASCIMENTO, Wanderson Flor do. Transgeneridade e Candomblés: Notas para um debate. Revista Calundu, vol. 3, n. 2, p. 123-141, 2019. https://doi.org/10.26512/revistacalundu.v3i2.28957

NONATO, Giu. Medium. Disponível em: https://medium.com/@giunonato

OAKLEY, Ann. Sex and Gender. Sex, Gender \& Society. New York: Harper, 1972.

OAKLEY, Ann. Interviewing women: a contradiction in terms. In: H. Roberts, (ed.). Doing Feminist Research. London: Routledge \& Kegan Paul, 1981.

OLIVEIRA, Eduardo David de; SOUZA, Marcilene Garcia de; PAULA, Maria José da Silva $S$. A questão de gênero no Candomblé. Disponível em: http://www.ifil.org/Biblioteca/souza.htm

ORGANIZAÇÃO DAS NAÇÕES UNIDAS. Declaração Universal dos Direitos Humanos. Assembleia Geral das Nações Unidas em Paris. 10 dez. 1948. Disponível em: http://www.dudh.org.br/wpcontent/uploads/2014/12/dudh.pdf

OXAGIYAN, Celso. Religião, homossexualidade, postura e que tais - Final. Informativo Tambor. Guararema, n. 33, 2002. 
OXALÁ, Adilson. Igbadu a Cabaça da Existência - Mitos da Tradição Nago revelados. Rio de Janeiro: Pallas Editora, 2005.

PEREIRA, Rodrigo; CHEVITARESE, André Leonardo. Por uma Arqueologia dos Candomblés: contribuições da ciência do passado aos estudos dos fenômenos religiosos. Revista Maracanan, vol. 20, p. 112-136, 2019.

PILÃO, Antonio Cerdeira; GOLDENBERG, Mirian. Poliamor e monogamia: construindo diferenças e hierarquias. Revista Ártemis - Estudos de Gênero, Feminismos e Sexualidades, vol. 13, n. 1, 2012.

POUPART, Jean. A entrevista de tipo qualitativo: considerações epistemológicas, teóricas e metodológicas. In: A Pesquisa qualitativa: enfoques epistemológicos e metodológicos. Petrópolis, RJ: Vozes, 2008.

PRANDI, Reginaldo. O Brasil com axé: candomblé e umbanda no mercado religioso. Estudos Avançados, vol. 18, n. 52, p. 223-238, 2004. https://doi.org/10.1590/S010340142004000300015

SANTOS, Erisvaldo Pereira; DALLAPICULA, Catarina. Travestilidades e transexualidades no Candomblé e na educação: Um ensaio a partir de experiências. Práxis Educacional, vol. 16, n. 39, p. 161-179, 2020. https://doi.org/10.22481/praxisedu.v16i39.6364

SANTOS, Milton Silva. Sexo, gênero e homossexualidade: o que diz o povo-de-santo paulista? Horizonte, vol. 6 , n. 12 , p.145-156, 2008.

SANTOS, Milton Silva. Mito, possessão e sexualidade no Candomblé. Revista do Núcleo de Estudos de Religião e Sociedade (NURES), n. 8, 2011. Disponível em: https://revistas.pucsp.br/nures/article/view/7216/5219.
SEPUlVEDA, Denize; SEPUlVEDA, Jose Antonio. Práticas conservadoras: Suas influências nas tessituras identitárias de gêneros e sexualidade. Periferia. Educação, Cultura \& Comunicação, vol. 9, n. 2, p. 16-37, 2017.

SHANKLE, Michael. The handbook of Lesbian, Gay, Bisexual, and Transgender public health: A practitioner's guide to service. Haworth Press, 2006.

SILVA, Fernanda de Moraes. Um ambiente de resistência e luta pela liberdade cidadã e culto religioso da população das mulheres transexuais e das travestis. Disponível em: https://antrabrasil.org/author/keilasimpson/

SOUZA, Daniela Barreto de; SOUZA, Adilio Junior de. Itan: entre o mito e a lenda. Letras escreve. v. 8, n. 3, p.99-113, 2018. http://dx.doi.org/10.18468/letras.2018v8n3.p99-113

STOLLER, Robert. A experiência transexual. Rio de Janeiro: Imago, 1982.

TEIXEIRA, Maria Lina Leão. Lorogun - identidades sexuais e poder no Candomblé. In: MOURA, Carlos Eugênio Marconde de (Org.). Candomblé desvendando identidades: novos escritos sobre a religião dos orixás. São Paulo: EMW Editores, 1987.

TERRIN, Aldo Natale. O sagrado off limits: a experiência religiosa e suas expressões. São Paulo: Loyola, 1998.

THE SANTA CRUZ COUNTY IN-QUEERY. Santa Cruz Lesbian, Gay, Bisexual \& Transgendered Community Center, vol. 9, 1996.

VOSGERAU, Dilmeire Sant'Anna Ramos; ROMANOWSKI, Joana Paulin. Estudos de Revisão: implicações conceituais e metodológicas. Revista Diálogo Educativo, vol. 14, n. 41, p. 165-189, 2014. 